\title{
DESENVOLVIMENTO LOCAL E OS SABERES DAS ARTESÃS
}

QUILOMBOLA: contribuições da educação ambiental na produção artesanal da comunidade quilombola de Conceição das Crioulas ${ }^{1}$

\author{
LOCAL DEVELOPMENT AND THE KNOWLEDGE OF \\ QUILOMBOLA ARTISANS: contributions of environmental education \\ in the artisanal production of the quilombola community of Conceição das \\ Crioulas
}

\begin{abstract}
Éder Batista da Silva
Eng. Florestal, Licenciado em Ciências Agrícolas, Mestre em Extensão Rural e Desenvolvimento Local, UFRPE, Recife - PE, Brasil eder7bs@gmail.com.
\end{abstract}

Maria Aparecida Tenório Salvador da Costa Professora do Programa Pós-Graduação em Ensino das Ciências, UFRPE, RECIFE - PE, Brasil aparecidatcosta@hotmail.com.

\section{Resumo}

Este texto traduz um recorte de uma pesquisa acadêmica desenvolvida com o objetivo de analisar a dialogicidade entre a extensão rural e a educação ambiental na promoção de mudanças sociais e desenvolvimento local na Comunidade Quilombola de Conceição das Crioulas, zona rural do município de Salgueiro - PE. O referido recorte tem por objetivo analisar o processo de construção do desenvolvimento local pelas artesãs da comunidade quilombola através da adoção da educação ambiental como estratégia de resistência dos valores culturais e fortalecimento do projeto político da comunidade quilombola. A pesquisa é de natureza qualitativa, onde os dados foram coletados através da análise documental, observações de campo e da realização de entrevistas semiestruturadas e analisados através da metodologia da Análise do Discurso - AD. Os sujeitos da investigação foram: artesãs, educadores e educadoras da comunidade. A educação ambiental adotada nos espaços de construção de conhecimentos da comunidade contribui de maneira direta para formação de uma nova visão de mundo dos sujeitos da comunidade quilombola.

Palavras chave: Educação não-formal. Quilombos. Ecologia de saberes. Saberes Tradicionais. Sustentabilidade.

1- O artigo é originado das contribuições pós-defesa da dissertação intitulada "Extensão Rural e Educação Ambiental: a experiência da Comunidade Quilombola de Conceição das Crioulas, no município de Salgueiro - PE” de autoria de Éder Batista da Silva, defendida no ano de 2019 no Programa de PósGraduação em Extensão Rural e Desenvolvimento Local - POSMEX, UFRPE, sob orientação da Prof.a Dr. ${ }^{a}$ Maria Aparecida Tenório Salvador da Costa. 


\begin{abstract}
This text reflects an excerpt from an academic research developed with the objective of analyzing the dialog between rural extension and environmental education in promoting social changes and local development in the Quilombola Community of Conceição das Crioulas, rural area of the municipality of Salgueiro - PE. This section aims to analyze the process of construction of local development by artisans of the quilombola community through the adoption of environmental education as a strategy to resist cultural values and strengthen the political project of the quilombola community. The research is of a qualitative nature, where data were collected through document analysis, field observations and semi-structured interviews and analyzed using the Discourse Analysis - AD methodology. The subjects of the investigation were: artisans, educators and educators from the community. The environmental education adopted in the knowledge building spaces of the community contributes directly to the formation of a new world view of the subjects of the quilombola community.
\end{abstract}

Keywords: Non-formal education. Quilombos. Ecology of knowledge. Traditional Knowledge. Sustainability.

\title{
Introdução
}

O presente texto traduz um recorte de uma pesquisa acadêmica desenvolvida que teve por objetivo geral: analisar a dialogicidade entre a extensão rural e a educação ambiental na promoção de mudanças sociais e desenvolvimento local na Comunidade Quilombola de Conceição das Crioulas, zona rural do município de Salgueiro - PE.

Neste sentido, o referido recorte tem como objetivo específico analisar o processo de construção do desenvolvimento local pelas artesãs da comunidade quilombola através da adoção da educação ambiental como estratégia de resistência dos valores culturais e fortalecimento do projeto político da comunidade quilombola.

A partir do entendimento de que a educação ambiental exerce um papel fundamental na compreensão identitária dos sujeitos da comunidade quilombola, o processo investigativo buscou, ainda, identificar como as práticas educativas da comunidade contribuem para o fortalecimento da autonomia das mulheres artesãs da própria comunidade, assim como a possibilidade de construção dos saberes que proporcionam novas posturas quanto ao manejo e utilização sustentável dos recursos do território da comunidade quilombola para produção da matéria prima a ser empregada nas atividades de produção artesanal. 
A comunidade Quilombola de Conceição das Crioulas está localizada no distrito de Conceição das Crioulas, zona rural do município de Salgueiro no sertão de Pernambuco (a $550 \mathrm{~km}$ da capital Recife) e dista aproximadamente $45 \mathrm{~km}$ da sede urbana desse município. Ocupa uma área territorial de aproximadamente 16.865,678 hectares $^{2}$ com aproximadamente 750 famílias divididas em 16 núcleos populacionais (sítios), que tem como principais atividades econômicas a agricultura familiar, a pecuária e a produção artesanal em fibras naturais, palha e barro.

A história da comunidade Conceição das Crioulas remonta ao início do século XVIII, com a chegada de seis negras à região, guiadas por Francisco José, um escravo rebelado, e inicialmente arrendaram uma porção de terra que, posteriormente, foi adquirida com recursos advindos do trabalho artesanal na produção e fiação do algodão. Registros da comunidade indicam que as terras que compõe o território original da comunidade foram adquiridas oficialmente pelas mulheres fundadoras da comunidade no ano de 1802, contudo a comunidade só foi oficialmente reconhecida como comunidade quilombola pelo Estado Brasileiro no ano de 2000.

Atualmente é considerada a maior e mais antiga comunidade quilombola do estado de Pernambuco e, dada a sua localização territorial, tem sofrido diversas problemáticas sociais em função dos longos períodos de escassez hídricas, precariedade da via de acesso a comunidade e conflitos com proprietários de terra vizinhos (latifúndio) que ao longo do tempo adentraram e tomaram para si áreas do território original da comunidade.

\section{O fio metodológico}

O presente estudo é de natureza qualitativa, no qual os dados foram coletados através da análise documental, observações de campo e da realização de entrevistas semiestruturadas. Os sujeitos da investigação foram compostos por: representantes do coletivo de mulheres artesãs, educadores e educadoras das escolas quilombolas da comunidade.

2- Área atual regularizada da comunidade. Contudo, de acordo com a Fundação Cultural Palmares, a comunidade ainda reivindica uma área maior que a atualmente regularizada, mais de 17.000 hectares, como sendo integrante do território originário de formação da comunidade quilombola. 
A técnica da análise documental foi utilizada para compreensão do conceito de sustentabilidade nos territórios de comunidades quilombolas rurais à luz dos pressupostos da ecologia de saberes e do desenvolvimento local sustentável, visando compreender o processo de construção do desenvolvimento local da comunidade quilombola estudada a partir do diálogo entre a educação ambiental e os saberes tradicionais da referida comunidade.

A sistematização, descrição e a análise das informações colhidas através de documentos e discursos dos sujeitos pesquisados tiveram como alicerce a Análise do Discurso - $\mathrm{AD}$, onde os discursos foram organizados e interpretados através do estabelecimento de seus sentidos.

Desta forma, são considerados como discurso tanto as falas dos sujeitos entrevistados, como os seus gestos e silêncios, assim como os discursos contidos nos documentos analisados. Para fundamentar a $\mathrm{AD}$, são adotadas as perspectivas apresentadas por: Dijk (2008) sobre o poder do discurso; e Couto, Couto e Borges (2015) sobre o discurso ecológico (Análise do Discurso Ecológico - ADE).

Os aportes teóricos para a compreensão dos objetivos da pesquisa estão fundamentados nas concepções de Leite (1999; 2008), que versa sobre o projeto político quilombola como instrumento de sustentabilidade desses territórios; Santos (2010) e Brandão (2013), que discutem a ecologia de saberes como um instrumento de diálogo entre o saber tradicional e as perspectivas de desenvolvimento social dos sujeitos locais; Buarque (2008), Leff (2009), Sachs (2008, 2009), Kronemberger (2011), que discutem a sustentabilidade dos territórios como perspectiva de construção do desenvolvimento local; Figueiredo (2007); Carvalho (2008; 2012); Luzzi (2012); Sorrentino et al (2013), que discutem a educação ambiental como uma demanda social; e Gohn (2010) e Graciani (2014) que analisam as perspectivas de formação crítica e emancipação dos sujeitos pela ótica da pedagogia social.

\section{Educação ambiental e o desenvolvimento local quilombola}

Historicamente os povos tradicionais na América Latina, em virtude da destruição dos seus valores culturais pela ação do colonizador europeu, foram alijados de processos educativos que valorizassem as particularidades de seus modos de vida, o 
Desenvolvimento local e os saberes das artesãs

Quilombola: contribuições da educação

ambiental na produção artesanal da comunidade

Éder Batista da Silva

quilombola de Conceição das Crioulas

Maria Aparecida Tenório Salvador da Costa

que resultou na destruição dos seus valores culturais pela imposição da visão eurocêntrica.

No Brasil, este processo de imposição dos valores culturais antrópicos não foi diferente, povos originários tiveram seus modos de vida totalmente destruídos em função da imposição da visão de mundo alicerçada nos fundamentos ideológicos dos colonizadores. É fato conhecido em nossa história que, desde o período colonial, a educação formal foi negada as populações periféricas do país, em especial as de origem negra que foram violentamente exploradas durante o período escravocrata brasileiro.

Durante esse período, perpetuou-se a crença de que pessoas negras num espaço escolar representaria um risco a "ordem social" e poderiam exercer uma "má influência" nesses espaços (FONSECA, 2001). Contudo, faz-se necessário destacar que essa visão preconceituosa tinha como objetivo afastar as populações negras do acesso à educação para que não pudessem se rebelar contra as injustiças sociais e os modos de vida da elite brasileira.

Como afirma Campos e Gallinari (2017, p. 203), a “educação ocupa um lugar importante na produção de conhecimento sobre si e sobre os outros, além de contribuir para a formação de quadros intelectuais e políticos".

O acesso à educação é um dos direitos humanos básicos listados na Carta Magna Brasileira (CF-1988) para a formação cidadã dos indivíduos. Contudo em pleno século $\mathrm{XXI}$, os povos tradicionais do Brasil ainda travam uma batalha diária para acesso e garantia das condições mínimas de qualidade da educação que recebem em seus devidos espaços territoriais, o que se configura numa batalha constante para garantir minimamente a preservação de sua identidade, sua cultura e seus valores sociais.

É de conhecimento comum que sistema formal de ensino, ou seja, a escola, representa um espaço de formação social que possibilita a construção de uma sociedade menos injusta e excludente, pois acredita-se que neste espaço as diferenças culturais podem ser expressas e respeitadas por todos (SOARES, 2008).

Contudo a formação educativa não está limitada exclusivamente aos espaços educativos formais, ela alcança outros espaços de nosso cotidiano, tais como: a igreja, a associação de trabalhadores, a feira, o sindicato, etc., são os chamados espaços de educativos não-formais, que cumprem o papel de suprir e promover a formação educacional que não é vivenciada através do sistema formal de ensino. 
A partir das discussões no campo educacional iniciadas na década de 1980, principalmente através dos movimentos sociais, foi possível enxergar que a educação para os povos quilombolas necessitava ser repensada, ou seja, concebida de maneira diferente da que até então estava sendo desenvolvida pelo sistema formal de ensino adotado no Brasil. Esta nova forma de pensar a educação tinha como objetivo corrigir as diversas problemáticas que foram identificadas, tais como: a reprodução do racismo, as inadequações dos materiais didáticos e organização do currículo escolar que não dialogavam com a realidades de vida os sujeitos deste recorte, etc. (MIRANDA, 2012).

Para Bezerra e Silva (2016, p. 5), o processo de escolarização dos territórios quilombolas do país é "marcado por negação, interdição e também por ruptura e fratura". Para as autoras, o território quilombola não é só um lugar de moradia, mas também um "lugar da memória, da ancestralidade, do saber fazer e de aprender juntos e de construir no presente o futuro" (p.2).

Apesar de ser considerada a maior comunidade quilombola de Pernambuco e uma das mais antigas do país, a Comunidade Quilombola de Conceição das Crioulas apresenta uma condição rara entre as comunidades de quilombo no Brasil, a de ser uma comunidade que possuí escolas em seu território que englobam todos os níveis da educação básica, desde o ensino infantil até o ensino médio, que dialogam com a sua realidade de vida (BEZERRA; SILVA, 2016).

No capitulo teórico que versa sobre a educação quilombola na dissertação que possibilitou a produção deste artigo, afirmei que quando a educação é pensada para dialogar com a realidade de vida dos sujeitos dos territórios quilombolas, esta poderá ser uma ferramenta de empoderamento e libertação social dos sujeitos.

\begin{abstract}
A educação quilombola de qualidade poderá garantir que os sujeitos envolvidos nos processos educativos, crianças, jovens, adultos, idosos, se empoderem de conhecimentos acerca de suas realidades e possam seguir trilhando a luta de seus ancestrais. Desta maneira, a educação cumprirá um de seus papeis primordiais, que é prover melhorias das condições sociais dos sujeitos das comunidades quilombolas através da formação crítica dos sujeitos (SILVA, 2019, p. 47-48).
\end{abstract}

Também destaquei, que a valorização dos conhecimentos acumulados pelos sujeitos desse grupo social ao longo do tempo, pelas suas práticas educacionais, 
possibilita o fortalecimento da identidade local dos sujeitos e a sustentabilidade do projeto político quilombola, que é de grande importância para a manutenção dos modos de vida das comunidades deste recorte social.

\begin{abstract}
A participação dos sujeitos mais experientes (mais vividos) das comunidades nos diferentes espaços educativos, seja ele formal ou não, é um diferencial em relação ao modelo de educação hegemônico no país, pois trazem consigo a memória viva de suas comunidades e conseguem repassar os conhecimentos que acumularam ao longo da vida para as crianças e membros mais jovens da comunidade, salvaguardando assim a história da comunidade e fortalecendo suas raízes (SILVA, 2019, p. 48).
\end{abstract}

A educação quilombola não se limita exclusivamente aos espaços formais do sistema de ensino, ou seja, unicamente ao ambiente escolar, ela é bem mais ampla e alcança os diversos espaços e práticas educativas não formais adotadas pelos diversos atores sociais que integra o universo quilombola. Compreende-se então, que ela é conjunto de práticas que abarcam também uma combinação de conhecimentos diversificados, concebidos no relacionamento com a natureza, no espaço de vida e na utilização racional dos recursos naturais de seus territórios, que se configura numa complexa rede de conhecimentos estruturados a partir de suas próprias experiências.

Um dos eixos norteadores da educação quilombola, é a preocupação com questões ambientais que envolve o território das comunidades quilombolas, desta forma as práticas educativas e ações de conscientização ambiental dos sujeitos quilombolas também não estão limitadas aos sujeitos vinculados a escola, ou seja, tal preocupação estende-se pelos diversos espaços formativos das comunidades, através ações que tenham a finalidade de promover a educação ambiental.

Para compreendermos o conceito de Educação Ambiental, faz-se necessário recorrer aos artigos $1^{\circ}$ e $2^{\circ}$ da Política Nacional de Educação Ambiental - PNEA (Lei Federal 9.795, de 27 de abril de 1999) que conceituam a Educação Ambiental (EA) e a estabelecem como sendo um componente essencial da educação do país que não se limita apenas às formas e aos processos educativos tradicionais, sendo esta uma temática mais ampla. 
Art. $1^{\circ}$ Entendem-se por educação ambiental os processos por meio dos quais o indivíduo e a coletividade constroem valores sociais, conhecimentos, habilidades, atitudes e competências voltadas para a conservação do meio ambiente, bem de uso comum do povo, essencial à sadia qualidade de vida $\mathrm{e}$ sua sustentabilidade.

Art. $2^{\circ}$ A educação ambiental é um componente essencial e permanente da educação nacional, devendo estar presente, de forma articulada, em todos os níveis e modalidades do processo educativo, em caráter formal e não-formal (BRASIL, 1999).

Este dispositivo legal tem por objetivo estabelecer as bases legais para compreensão do conceito de educação ambiental, assim como seus princípios básicos e objetivos fundamentais, elencados nos Art. $4^{\circ}$ e $5^{\circ}$ da referida lei.

Desta forma, é possível compreender que a PNEA está alicerçada sob uma visão humanística e holística para alcançar o objetivo de salvaguarda do ambiente que vivemos e parte do pressuposto que, para compreensão da realidade, é necessário que exista uma formação da consciência crítica dos sujeitos acerca da temática ambiental e social que fortaleça a cidadania dos indivíduos no processo de construção de uma sociedade ambientalmente equilibrada e socialmente justa.

\begin{abstract}
Art. $4^{\circ}$ São princípios básicos da educação ambiental: I - o enfoque humanista, holístico, democrático e participativo; [...] III - o pluralismo de ideias e concepções pedagógicas, na perspectiva da inter, multi e transdisciplinaridade; IV - a vinculação entre a ética, a educação, o trabalho e as práticas sociais; [...] VIII - o reconhecimento e o respeito à pluralidade e à diversidade individual e cultural.

Art. $5^{\circ}$ São objetivos fundamentais da educação ambiental: I - o desenvolvimento de uma compreensão integrada do meio ambiente em suas múltiplas e complexas relações, envolvendo aspectos ecológicos, psicológicos, legais, políticos, sociais, econômicos, científicos, culturais e éticos; [...] III - o estímulo e o fortalecimento de uma consciência crítica sobre a problemática ambiental e social; [...] V - o estímulo à cooperação entre as diversas regiões do País, em níveis micro e macrorregionais, com vistas à construção de uma sociedade ambientalmente equilibrada, fundada nos princípios da liberdade, igualdade, solidariedade, democracia, justiça social, responsabilidade e sustentabilidade; [...] VII - o fortalecimento da cidadania, autodeterminação dos povos e solidariedade como fundamentos para o futuro da humanidade (BRASIL, 1999).
\end{abstract}

A Educação Ambiental possibilita que os indivíduos reflitam acerca das problemáticas e mazelas sociais produzidas pela visão hegemônica da sociedade em que vive, além de propor novas alternativas que busquem contornar e reduzir as desigualdades sociais de seu tempo. Esta concepção pode ser considerada como uma 
visão de contraposição dos conflitos sociais e ambientais impostos pela sociedade hegemônica e apresenta um significativo de mobilização para emancipação de grupos sociais em situação de vulnerabilidade (BIAGE DE ANDRADE; DOS SANTOS PINTO, 2017).

Para Da Silva Rosa (2015, p. 212), a educação ambiental pode ser compreendida como:

\begin{abstract}
Como uma estratégia de reflexão para a sociedade ou grupo pelo qual é desenvolvida no intuito de novamente estabelecer valores e criar uma nova identidade ao indivíduo, considerando que este só poderá ser formado de modo a demonstrar o amadurecimento ambiental com base em um projeto que o insira como formador de opinião e não apenas como cumpridor de ordens ou regras.
\end{abstract}

Para Thiago (2011), a educação ambiental deve ser compreendida como sendo um processo crítico da realidade social, que objetiva a transformação da realidade na medida que busca alcançar a igualdade de condições de acesso e uso dos recursos naturais de forma justa e socialmente sustentável.

Para Barros (2012) esta transformação envolve a compreensão da complexa relação - homem com ambiente e o seu território -, além de seus anseios, expectativas, satisfações e insatisfações, pois cada indivíduo percebe, reage e responde de maneiras distintas ao ambiente que ocupa. A autora, ainda defende que os sujeitos de povos tradicionais apresentam uma relação bastante direta com o meio ambiente, através de uma visão ambiental que permite uma melhor compreensão do contexto socioambiental dos territórios que ocupam, pois, "a percepção ambiental é algo fundamental se pensarmos no grau de envolvimento dos indivíduos que pertencem a esses grupos com a natureza, sendo esta primordial para sua sobrevivência" (p. 218 - 219).

Compreende-se então que, um dos maiores desafios posto a educação ambiental é o de promover o diálogo com as ações de desenvolvimento praticadas no país, em especial com a sustentabilidade das comunidades tradicionais que estão localizadas no meio rural, que demandam maior aprofundamento das relações sociais entre os diversos sujeitos que estão envolvidos nesse processo.

Ao longo do tempo, o conceito de sustentabilidade tem remetido a diversas discussões, que o define basicamente pela visão de mundo de quem o analisa, contudo, existe um consenso acerca da necessidade de se buscar novas estratégias de 
desenvolvimento que possam ser consideradas ambiental, econômica e socialmente viáveis.

Neste sentido, Pinto (2006, p. 52) afirma que:

\begin{abstract}
A Educação Ambiental pode ser considerada como um instrumento eficiente na potencialização do desenvolvimento local sustentável, considerando que a sua prática induz à mudança de hábitos, atitudes, valores, comportamentos e conceitos, levando também a comunidade a discussões, o que dá um novo significado às práticas sociais, delineando uma nova realidade que começa a ser transformada a partir de atitudes conscientes das pessoas.
\end{abstract}

A autora ainda conclui que:

\begin{abstract}
Para que a Educação Ambiental contribua com a potencialização do desenvolvimento local, é preciso que a trajetória do seu processo educativo não se resuma exclusivamente à escola. Deve estar voltada também para uma rede de ações e relações estabelecidas por meio de um conjunto de práticas desenvolvidas por diversos atores sociais que exerçam um papel fundamental para o seu desenvolvimento e sua concretização (PINTO, 2006, p. 52).
\end{abstract}

Assim, é possível concluir que a educação ambiental pode ser considera como uma importante ferramenta que nos possibilita repensar e eliminar práticas agressivas e insustentáveis ao ambiente natural, modificando hábitos danosos, comuns em nosso diaa-dia, para alcançar um desenvolvimento local que possa ser considerado sustentável e propor novas formas de pensar.

Nesse sentido, Boaventura de Souza Santos (2010) defende que os processos sustentáveis concebidos no seio de uma comunidade quilombola, não só possibilitam formas alternativas de construção e reconstrução de novos conhecimentos, bem como viabilizam possíveis ações para alcançar um processo de desenvolvimento local que seja considerado sustentável do ponto de vista social e ambiental.

\title{
A produção artesanal de Conceição das Crioulas
}

A produção artesanal da comunidade Quilombola de Conceição das Crioulas é uma herança histórica, que remonta a época de fundação da comunidade ainda no século XVIII, é considerada uma tradição feminina associada aos processos de resistência e luta da comunidade quilombola. Apesar da produção artesanal da comunidade ser uma 
constante de seu cotidiano, essa atividade foi deixada em segundo plano por um longo tempo e só numa fase mais recente de sua história, quando a comunidade atravessava um período de grandes dificuldades, a produção artesanal foi resgatada de maneira mais intensa como uma possibilidade de promoção de renda.

Ao longo do tempo, o barro, o caroá, o catolezeiro, a madeira e a linha de algodão foram utilizadas como matéria prima básica para a produção artesanal da comunidade, que possibilitava não só uma geração de renda, mas também uma atividade educativa que envolvesse crianças, jovens e adultos. Assim panelas, pratos, copos, brincos, colares, bolsas, flores, bonecas, colheres de pau, cabides foram produzidos pelas mãos habilidosas das mulheres artesãs da comunidade quilombola que contam a sua história e reafirmam a identidade étnica e cultural de Conceição das Crioulas.

A produção artesanal da comunidade, que é protagonizada pelas mulheres artesãs, utiliza como matéria prima recursos naturais que podem ser considerados, até certo ponto, escassos na caatinga, principalmente em virtude das condições climáticas peculiares da região em que a comunidade está localizada. Assim a produção artesanal exige que a comunidade tome certos cuidados para que os recursos naturais da caatinga sejam utilizados de maneira sustentável.

Essa visão de sustentabilidade não engloba apenas os aspectos ambientais da exploração dos recursos da caatinga, ela envolve também a questões sociais, econômicas e identitárias da própria comunidade. A exemplo dos produtos produzidos a partir da fibra do caroá, Neoglaziovia variegata, uma bromeliácea nativa da caatinga nordestina, a qual é empregada pela comunidade para produção de bolsas, painéis, jogos americanos e bonecas.

As bonecas produzidas a partir da fibra do caroá representam um grande diferencial na produção artesanal, pois retratam a resistência das mulheres negras da comunidade e homenageiam a distintas lideranças da comunidade ao longo do tempo. Inicialmente criada para homenagear uma de suas fundadoras, a comunidade hoje produz onze bonecas, que homenageiam onze mulheres da comunidade: parteiras, educadoras e agriculturas da região, que são comercializadas junto com um encarte contando a história da pessoa retratada pela boneca. 
Desenvolvimento local e os saberes das artesãs

Quilombola: contribuições da educação

ambiental na produção artesanal da comunidade

Éder Batista da Silva

quilombola de Conceição das Crioulas

Maria Aparecida Tenório Salvador da Costa

Entre as homenageadas, estão mulheres que hoje são referências vivas na comunidade, pois compreendem que as mulheres devem ter sua importância reconhecida ainda quando estão em vida.

É importante reconhecer o protagonismo das mulheres da comunidade, mas em vida. Muitas vezes só se homenageia a pessoa após a morte, mas elas precisam saber que são importantes ainda em vida. Eu sou uma das mulheres homenageadas, fico feliz sabendo que meu trabalho com as mulheres, com os jovens, com as meninas para fortalecer a nossa identidade como quilombola é reconhecido. Também tem o reconhecimento enquanto educadora, eu ensino a cuidar do meio ambiente, eu levo as crianças para conhecer o território da nossa comunidade. Muitas mulheres daqui me vê como uma referência de luta (educadora e artesã).

Destaca-se aqui, que a produção artesanal representa uma grande importância social, cultural e histórica para a comunidade. Essa atividade é vista como cartão de visitas a comunidade fora da Município de Salgueiro.

O artesanato surgiu com a intenção de manter a nossa história, mas também é uma terapia. O mais importante da peça não é o dinheiro, é a história dela, a história de quem fez ela. É importante quando uma menina começa a aprender a fazer as peças que ela saiba que ainda não é possível viver só do artesanato, mas esse já provém um complemento de renda interessante, além de reafirmar a nossa história (educadora e artesã).

Contudo, a produção artesanal só se tornou vitrine da comunidade a partir do ano de 2001, quando as artesãs locais foram convidadas a participar da FENEARTE $^{3}$ no Centro de Convenções de Pernambuco.

As mulheres artesãs da comunidade lidam com uma realidade local que, muitas vezes, desestimulava a produção artesanal, o que justifica o porque desta atividade ter sido deixada em segundo plano e restrita a poucos grupos de pessoas da comunidade por um longo tempo.

Em outros lugares a gente pediria dinheiro, açúcar, café emprestado ao vizinho, aqui a gente pede água. Se não cuidar bem da minha cisterna, não

3- FENEARTE é a Feira Nacional de Negócios do Artesanato, evento promovido anualmente pelo governo do estado de Pernambuco no Centro de Convenções de Pernambuco em Olinda e tem por finalidade dar visibilidade e fortalecer a produção artesanal do Estado. 
vou poder contar com o vizinho toda hora que precisar porque a água dele também vai acabar (artesã).

Por esse relato, compreende-se que a comunidade apresenta uma consciência da necessidade de uma atenção especial com os recursos hídricos locais, tais como: não uso do fogo para limpeza de terras para cultivo agrícola, proteção dos recursos hídricos, manutenção da vegetação da caatinga, etc., pois isto impacta diretamente na oferta de matéria prima disponível para trabalhar.

A preocupação com a sustentabilidade dos recursos locais pela comunidade quilombola, pela ótica da educação ambiental, pode ser evidenciada nas ações de um coletivo criado por mulheres artesãs, que tem a finalidade promover um trabalho de exploração racional recursos da caatinga como matéria prima.

De acordo com as artesãs, esse grupo de trabalho tem, entre suas finalidades, o aperfeiçoamento das técnicas de retiradas das matérias primas, a melhoria da qualificação das pessoas envolvidas nesse processo e a conscientização da comunidade.

É necessário que a pessoa aprenda a retirar a matéria prima e utilizar os recursos, mas precisamos que alguém vá ensinando para que o número de pessoas que fazem isso vá aumentando, mas que seja de maneira organizada para não destruir (educadora e artesã).

Assim, para as artesãs é necessário que se demonstre como fazer, os cuidados que devem ser adotados e até que ponto se pode intervir sem que haja danos além daqueles que o ambiente natural é capaz de suportar e se reestabelecer sozinho.

\begin{abstract}
A gente não quer muita gente retirando matéria prima, queremos que as pessoas da comunidade tenham consciência que é preciso ter um controle sobre o que retiramos para não provocar desperdício e nem destruir a caatinga. A gente leva esse conhecimento para dentro das escolas para que as crianças também aprendam e tenham consciência dessa preocupação com nosso trabalho e com o meio ambiente (educadora e artesã).
\end{abstract}

Para as artesãs, além da manutenção dos seus valores culturais, a produção artesanal da comunidade também é considerada como um importante instrumento de debate sobre as questões de sustentabilidade do território da comunidade. Ou seja, esse 
debate fomenta discussões acerca da sustentabilidade dos recursos naturais da comunidade, das questões de gênero e valorização do trabalho das mulheres, dá inclusão dos jovens para salvaguarda da memorial biocultural da comunidade, da valorização das experiências de vidas, etc.

Aqui é possível compreender, que a comunidade se utiliza da concepção da educação ambiental para estimular uma apropriação crítica dos saberes em seu ambiente de vida. Ressalta-se que, no universo quilombola, essa prática não é algo isolado, ela é fruto de uma combinação de conhecimentos acumulados ao longo do tempo, que se tornam ainda mais colorido de saberes à medida que a comunidade aumenta seu nível de estruturação política e cultural.

$\mathrm{O}$ relato de uma das educadoras entrevistadas, nos mostra o quanto esse engajamento dos sujeitos da comunidade é importante para formação da consciência crítica da própria comunidade.

\footnotetext{
Essa é uma comunidade que tira muito o aluno das quatro paredes para ir mostrar o próprio território... assim a gente tá sempre mostrando o que a gente pode fazer com o que temos, [...] a gente faz, o que a gente fala, a gente vai mostrar na prática pros nossos estudantes (educadora).
}

Ao considerarmos, que as comunidades quilombolas são sistemas culturais que estão em constante evolução, se faz necessário que os sujeitos desses espaços sociais também estejam em processo de aquisição de novos saberes para ressignificação dos conhecimentos acumulados. Ou seja, o processo de construção de conhecimento citado pela educadora entrevistada nos permite concluir que o diálogo entre a escola quilombola e os espaços educativos não formais da comunidade possibilita a formação da consciência crítica da comunidade, em especial no que se refere aos aspectos políticos, sociais, econômicos e ambientais.

Esse processo também ocorre em sentido inverso, quando os diversos atores sociais da comunidade adentram também no ambiente escolar formal para demonstrar como são realizadas as ações do cotidiano em outros espaços de vida, e levam consigo a visão da educação ambiental como uma ferramenta norteadora de suas ações enquanto sujeitos quilombolas rurais. 
Ressalta-se que os saberes encontrados no seio das comunidades quilombolas rurais também permitem a construção de novos espaços de reflexão e diálogo acerca dos aspectos socioambientais das próprias comunidades, que podem ser compreendidos como sendo uma tradução da manutenção de seus aspectos de identidade e culturalidade político-social, que buscam a salvaguarda dos saberes tradicionais acumulados pelos sujeitos quilombolas ao longo do tempo.

Assim, compreende-se que a educação ambiental adotada pelos diversos espaços de construção de conhecimentos da comunidade quilombola de Conceição das Crioulas, contribui de maneira direta para formação de uma nova visão de mundo dos sujeitos da comunidade, na medida em que se propõe a questionar a visão hegemônica de mundo para buscar a formação de uma consciência crítica dos sujeitos da comunidade no que se refere ao uso dos recursos naturais do território quilombola.

\section{Considerações finais}

O trabalho investigativo realizado possibilita afirmar que as artesãs da comunidade demonstraram uma grande preocupação com a manutenção dos recursos naturais que são encontrados em território.

$\mathrm{O}$ estímulo e adoção de práticas educativas voltadas às realidades da comunidade quilombola pelo coletivo de mulheres artesãs tem por objetivo o alcance de melhorias sociais através de ações, que estimulem a qualidade de vida e a concepção sociopolítica dos sujeitos da referida comunidade.

A educação ambiental tem sido empregada como uma importante ferramenta de mobilização social da comunidade para tratar das questões de sustentabilidade do território quilombola de Conceição das Crioulas.

A comunidade quilombola tem como prática a integração entre a educação formal e os espaços educativos não formais, para fortalecimento da identidade quilombola e estimular a participação dos jovens em ações voltadas para as questões de sustentabilidade da comunidade que alcance os recortes de gênero, questões ambientais, geração de renda e participação social.

A produção artesanal na comunidade tem como objetivo não só a geração de renda, bem como o fortalecimento da identidade e a valorização do trabalho das 
mulheres artesãs, além do estimulo a comunidade para conscientização da exploração racional dos recursos utilizados como matéria prima.

\section{Referências}

BARROS, Juliana Ramalho. A percepção ambiental dos quilombolas Kalunga do engenho e do vão de almas acerca do clima e do uso da água. Ateliê Geográfico, vol. 6, n. 4, p.216-236, dez. 2012. Disponível em: https://doi.org/10.5216/ag.v6i4.21980. Acesso em: 08 out. 2017. https://doi.org/10.5216/ag.v6i4.21980

BIAGE DE ANDRADE, Leonardo; DOS SANTOS PINTO, Vicente Paulo. Os Riscos, a Vulnerabilidade Ambiental e o Estado Capitalista: a proposta de uma Educação Ambiental como ato político. REMEA, [S.1.], v. 34, n. 3, p. 207-225, dez. 2017. Disponível em: https://periodicos.furg.br/remea/article/view/7232. Acesso em: 29 jan. 2018. https://doi.org/10.14295/remea.v34i3.7232

BEZERRA, Marinalva Rita; SILVA, Delma Josefa. Gestão escolar quilombola: a experiência curricular da escola Bevenuto Simão-Conceição das Crioulas-PE. IX Colóquio Internacional Paulo Freire, 2016. Disponível em: http://coloquio.paulofreire.org.br/participacao/index.php/coloquio/ixcoloquio/paper/vie w/641. Acesso em: 25 jun. 2018.

BRANDÃO, Carlos Rodrigues. Saber para si, saber com os outros. In.: SORRENTINO, Marcos (Org.). Educação ambiental e políticas públicas: conceitos, fundamentos e vivências. Curitiba: Appris, 2013. 499p. p. 89 - 107.

BRASIL. [Constituição (1988)]. Constituição da República Federativa do Brasil. Brasília, DF, 1988. Disponível em:

http://www.planalto.gov.br/ccivil 03/Constituicao/Constituicao.htm. Acesso em: 02 jul. 2017.

BRASIL. LEI FEDERAL Nº 9.795, de 27 de abril de 1999. Dispõe sobre a educação ambiental, institui a Política Nacional de Educação Ambiental e dá outras providências. Disponível em: http://www.planalto.gov.br/CCiVil_03/LEIS/L9795.htm. Acesso em 20 jun. 2018.

BUARQUE, Sergio C. Construindo o desenvolvimento local sustentável. 4.ed. - Rio de Janeiro: Garamond, 2008. 180p.

CAMPOS, Margarida Cassia; GALLINARI, Tainara Sussai. A educação escolar quilombola e as escolas quilombolas no Brasil. Revista Nera, v. 20, n. 35, p. 199-217, 2017. Disponível em: http://revista.fct.unesp.br/index.php/nera/article/view/4894. Acesso em: 23 jun. 2018. https://doi.org/10.47946/rnera.v0i35.4894 
CARVALHO, Isabel Cristina de Moura. A invenção ecológica: narrativas e trajetórias da educação ambiental no Brasil. 3. ed. - Porto Alegre: Editora da UFRGS, 2008.

CARVALHO, Isabel Cristina de Moura. Educação ambiental: a formação do sujeito ecológico. $6^{\text {a }}$ ed. - São Paulo: Cortez, 2012.

COUTO, Hildo Honório; COUTO, Elza Kioko Nakayama Nenoki do; BORGES, Lorena Araújo de Oliveira. Análise do discurso ecológica - ADE. Campinas, SP: Pontes Editores, 2015. (Coleção: Linguagem e Sociedade, v.9).

DA SILVA ROSA, Teresa e et al. A educação ambiental como estratégia para a redução de riscos socioambientais. Ambiente \& Sociedade, São Paulo, vol. 18, n. 3, p. 211-230, set. 2015. Disponível em: http://dx.doi.org/10.1590/1809-4422ASOC1099V1832015. Acesso em: 10 out. 2017. https://doi.org/10.1590/1809-4422ASOC1099V1832015

DIJK, Teun A. Van. Discurso e Poder. São Paulo: Contexto, 2008, 281p.

FIGUEIREDO, João B. A. Educação ambiental dialógica: as contribuições de Paulo Freire e a cultura sertaneja nordestina. Fortaleza: Edições UFC, 2007. 395p.

FONSECA, Marcus Vinícius. As primeiras práticas educacionais com características modernas em relação aos negros no Brasil. In: CAMPOS, Maria Machado Malta et al. (Org.). Negro e educação: presença do negro no sistema educacional brasileiro. São Paulo: Ação Educativa/ANPED, 2001. p. 11-36. Disponível em: http://www.dominiopublico.gov.br/download/texto/me002032.pdf. Acesso em: $10 \mathrm{jul}$. 2018.

GRACIANI, Maria Stela Santos. Pedagogia Social. São Paulo: Cortez, 2014.

GOHN, Maria Glória. Educação não formal e o educador social: atuação no desenvolvimento de projetos sociais. São Paulo: Cortez, 2010. (Coleção questões da nossa época, v. 1)

KRONEMBERGER, Denise. Desenvolvimento local sustentável: uma abordagem prática. São Paulo: Editora Senac São Paulo, 2011.

LEITE, Ilka Boaventura. Quilombos e quilombolas: cidadania ou folclorização? Horizontes Antropológicos, Porto Alegre, ano 5, n. 10, p. 123-149, maio 1999. Disponível em: http://www.scielo.br/pdf/ha/v5n10/0104-7183-ha-5-10-0123.pdf. Acesso em 18 mai. 2018. https://doi.org/10.1590/S0104-71831999000100006

LEITE, Ilka Boaventura. O projeto político quilombola: desafios, conquistas e impasses atuais. Revista Estudos Feministas, vol. 16, n. 3, p. 965-977, 2008. Disponível em: http://www.scielo.br/pdf/ref/ v16n3/15.pdf. Acesso em: 11 jul. 2017. https://doi.org/10.1590/S0104-026X2008000300015

LEFF, Enrique. Saber ambiental: Sustentabilidade, racionalidade, complexidade, poder. 7. ed. - Petrópolis, RJ: Editora Vozes, 2009. 
LUZZI, Daniel. Educação e meio ambiente: uma relação intrínseca. Barueri, SP: Manole, 2012.

MIRANDA, Shirley Aparecida de. Educação escolar quilombola em Minas Gerais: entre ausências e emergências. Rev. Bras. Educ., Rio de Janeiro, v. 17, n. 50, p. 369383, ago. 2012. Disponível em: http://dx.doi.org/10.1590/S1413-24782012000200007. Acesso em: 10 jul. 2018. https://doi.org/10.1590/S1413-24782012000200007

PINTO, Edilene Barbosa. Educação ambiental em área semiárida da Bahia: uma contribuição para a gestão. Recife: Fundação Joaquim Nabuco, Ed. Massangana, 2006. $166 \mathrm{p}$.

SACHS, Ignacy. Desenvolvimento: includente, sustentável, sustentado. Rio de Janeiro: Garamond, 2008. 152p.

SACHS, Ignacy. Caminhos para o desenvolvimento sustentável. Org.: Paula Yone Stroh. Rio de Janeiro: Garamond, 2009. 96p.

SANTOS, Boaventura de Sousa. A Gramática do Tempo: Para uma Nova Cultura Política. 3. ed. - São Paulo: Cortez, 2010. (Coleção: Para um Novo Senso Comum, v. 4).

SILVA, Eder Batista da. Extensão rural e educação ambiental: a experiência da comunidade quilombola de Conceição das Crioulas, no município de Salgueiro - PE. 2019. 125f. Dissertação (Mestrado em Extensão Rural e Desenvolvimento Local) Universidade Federal Rural de Pernambuco, 2019.

SOARES, Edimara Gonçalves. Do quilombo à escola: os efeitos nefastos das violências sociais silenciadas. 2008. 130 fls. Dissertação (Mestrado em Educação) Universidade Federal do Paraná, Curitiba, 2008.

SORRENTINO, Marcos e et al. Comunidade, identidade, diálogo, potência de ação e felicidade: fundamentos para educação ambiental. In.: SORRENTINO, Marcos (Org.). Educação ambiental e políticas públicas: conceitos, fundamentos e vivências. Curitiba: Appris, 2013. 499p. p. 21 - 622.

THIAGO, Fernando. A comunidade quilombola do Cedro, Mineiros-GO: Etnobotânica e educação ambiental. 2011. 109f. Dissertação (Mestrado em Ciências Ambientais) - Universidade do Estado de Mato Grosso, 2011. 